\title{
Renal Stromal Expression of Oestrogen and Progesterone Receptors in Chronic Pyelonephritis as Compared to Normal Kidneys
}

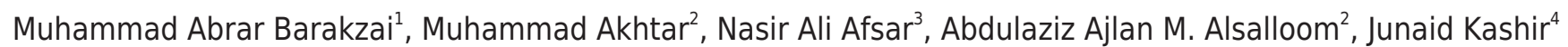
and Turki O. Al Hussain ${ }^{2}$

${ }^{1}$ Department of Pathology, College of Medicine, Alfaisal University, Riyadh, Saudi Arabia

${ }^{2}$ Department of Pathology, College of Medicine, Qassim University, Saudi Arabia

${ }^{3}$ Department of Pharmacology, College of Medicine, Alfaisal University, Riyadh, Saudi Arabia

${ }^{4}$ Department of Anatomy, College of Medicine, Alfaisal University, Riyadh, Saudi Arabia

\begin{abstract}
Objective: To determine and compare the distribution of oestrogen and progesterone receptors (ER and PR) expression between normal kidneys and chronic pyelonephritis.

Study Design: Comparative-descriptive study.

Place and Duration of Study: King Faisal Specialist Hospital and Research Centre, and Alfaisal University, Riyadh, Saudi Arabia, between January 2017 and December 2018.

Methodology: Renal specimens, including 41 chronic pyelonephritis, and 21 healthy specimens were examined. ER/PR expression was determined immunohistochemically, termed focal if $<50 \%$ of nuclei stained positively, and diffuse when $>50 \%$. The intensity of staining was labelled weak (pale), moderate or strong.

Results: Majority of samples showed presence of diffuse ER ( $82.9 \%$ diseased; $71.4 \%$ healthy) and focal PR $(53.7 \%$ diseased; $76.2 \%$ healthy), mostly with strong intensity. ER and PR distribution whether focal or diffuse, correlated with each other in $41.9 \%$. All proportions comparisons showed $p$ values greater than 0.05 .

Conclusion: There was a trend of diffuse renal stromal expression of ER and PR in chronic pyelonephritis as compared to healthy specimens. However, the difference did not reach statistical significance.
\end{abstract}

Key Words: Oestrogen receptor, Progesterone receptor, Chronic pyelonephritis, Renal cancer, Renal stroma.

How to cite this article: Barakzai MA, Akhtar M, Afsar NA, Alsalloom AAM, Kashir J, Hussain TOA. Renal Stromal Expression of Oestrogen and Progesterone Receptors in Chronic Pyelonephritis as Compared to Normal Kidneys. J Coll Physicians Surg Pak 2020; 30(08):857-862.

\section{INTRODUCTION}

The renal stromal expression of oestrogen and progesterone receptors (ER and PR), has been reported in neoplastic as well as non-neoplastic renal diseases. ${ }^{1}$ Recently, a link between chronic inflammation and cancer has been suggested, including hormone-dependent cancers. ${ }^{2}$ Further, the inflammatory response may be modulated by ER. ${ }^{3}$ Thus, a complex interplay between inflammation, gonadal hormones and carcinogenesis may exist.

Correspondence to: Dr. Muhammad Abrar Barakzai, Department of Pathology, College of Medicine, Alfaisal University, Riyadh, Saudi Arabia

E-mail: abarakzai@alfaisal.edu

Received: November 05, 2019; Revised: July 16, 2020;

Accepted: August 10, 2020

DOI: https://doi.org/10.29271/jcpsp.2020.08.857
Oestrogen induces cellular growth via overexpression of a nuclear transcription factor MYC, showing poor patient outcome in breast cancer. ${ }^{4}$ Similarly, Wnt signalling, associated with MYC, is found associated with colorectal cancers. ${ }^{5}$ MYC is a recognised oncogene in human renal cell carcinoma (RCC) also. ${ }^{6}$ Similarly, increased expression of oestrogen-related receptor alpha (ERR $\alpha)$, an orphan nuclear receptor, is an unfavourable cancer prognostic marker. ${ }^{7}$ Thus, oestrogen may be involved in the development of RCC.

Similarly, progesterone may promote cellular proliferation and carcinogenesis through various pathways including NFKB and RANKL. ${ }^{8}$ Recently, this pathway has been implicated in bone metastasis and poor prognosis in RCC. ${ }^{9}$ Interestingly, the expression of ER and PR is well observed in mixed epithelial stromal tumours of the kidney ${ }^{10}$ and angiomyolipoma. ${ }^{11}$ In contrast, oestrogen receptor $\beta$ has been suggested to inhibit carcinogenesis, ${ }^{12,13}$ pointing towards a complex role of sex hormones incarcinogenesis. 
Thus, chronic inflammation, like chronic pyelonephritis, may be associated with changes in sex hormone receptor expression, leading to long term effects, including neoplastic transformation. It is important to explore and document renal mesangial ER/PR expression in response to chronic pyelonephritis to further elucidate the underlying pathogenesis of malignant transformation. This could have implications in devising an evidence-based therapeutic approach. Hence, this study was designed to evaluate the stromal ER/PR expression in pyelonephritic kidneys as compared to healthy renal tissue.

\section{METHODOLOGY}

This comparative-descriptive study was conducted at the section of Anatomic Pathology, King Faisal Specialist Hospital and Research Centre (KFSH\&RC), and Departments of Pathology and Pharmacology, Alfaisal University, both at Riyadh, Saudi Arabia between January 2017 and December 2018. A total of 62 tissue specimens were included, including 41 nephrectomy specimens of non-functioning chronic pyelonephritiskidneys, and 21 healthy renal nephrectomy specimens removed for renal neoplasm from January 2010 to December 2014 from the Department of Pathology and Laboratory Medicine at KFSH\&RC. Immunohistochemistry was performed on one representative block containing such stroma using antibodies against ER and PR (Clone 6F11 and Clone 1E2 respectively; Ventana, Tucson, AZ, USA), on an automated slide stainer (Ventana Bench Mark, Tucson, AZ, USA). All tissue samples were fixed in $10 \%$ buffered formalin, and embedded in paraffin. Sections of 3-4 $\mu \mathrm{m}$ thickness were mounted on positively charged super frost slides and dried in an oven for one hour at $60^{\circ} \mathrm{C}$. The sections were then deparaffinised in xylene and rehydrated in graded ethanol. For epitope retrieval, the tissue sections were heated (microwave) in Tris-EDTA ( $\mathrm{pH}$ 9.0) for 16 minutes at $450 \mathrm{~W}$. The sections were then cooled down gradually to room temperature and washed with running tap water. Endogenous peroxidase was blocked by incubating the tissue in $3 \%$ hydrogen peroxide at room temperature for 10 minutes and washed with distilled water. The tissue samples were incubated with primary antibodies for 30 minutes at room temperature. Then, immune detection was performed with the 2-step polylabeling method using the envision system (Ventana, Tucson, AZ, USA) with diaminobenzidine (DAB) chromogen as a substrate. The slides were counter-stained by haematoxylin and finally mounted with distrine-pthaline xylene (DPX).

A nuclear brownstaining was considered as a positive result and complete absence as negative. The percentage of positive staining nuclei in the foci of stromal proliferation was calculated by counting. The percentage of the positive staining was called focal when $<50 \%$ of the nuclei showed positivity, or diffuse when $>50 \%$ showed positive staining. The semi-quantitative intensity of staining was assigned as weak (pale staining), strong (darkstaining) or intermediate.

The qualitative data was shown as frequency and percentage. The age was expressed as median and interquartile range
(IQR). Chi-square test, Fisher's exact test, odds ratios and correlation (Spearman's rho) between expression and intensity of ER and PR between groups was computed using SPSS ver 19. A pvalue $<0.05$ was considered significant.

\section{RESULTS}

A total of 62 renal samples were included from different individuals, including 41 patients of chronic pyelonephritis and 21 healthy specimens. The baseline characteristics of the study population are given in Table I. The age of the patients ranged between 3 and 82 years of age (median 34, IQR 14.75-55.25).

Table I: Baseline characteristics of study population and comparison betweengroups.

\begin{tabular}{|c|c|c|c|c|}
\hline Diagnosis & $\mathbf{N}$ & & $n$ & $\%$ \\
\hline \multicolumn{5}{|c|}{ Side (kidney) } \\
\hline \multirow{2}{*}{ Healthy } & 21 & Right & 9 & 42.9 \\
\hline & & Left & 12 & 57.1 \\
\hline \multirow{2}{*}{ Diseased } & 41 & Right & 22 & 53.7 \\
\hline & & Left & 19 & 46.3 \\
\hline \multicolumn{5}{|c|}{ ER percentage } \\
\hline \multirow{2}{*}{ Healthy } & 21 & Focal & 6 & 28.6 \\
\hline & & Diffuse & 15 & 71.4 \\
\hline \multirow{2}{*}{ Diseased } & 41 & Focal & 7 & 17.1 \\
\hline & & Diffuse & 34 & 82.9 \\
\hline \multicolumn{5}{|c|}{ ER intensity } \\
\hline \multirow{2}{*}{ Healthy } & 21 & Moderate & 3 & 14.3 \\
\hline & & Strong & 18 & 85.7 \\
\hline \multirow{2}{*}{ Diseased } & 41 & Moderate & 11 & 26.8 \\
\hline & & Strong & 30 & 73.2 \\
\hline \multicolumn{5}{|c|}{ PR percentage } \\
\hline \multirow{2}{*}{ Healthy } & 21 & Focal & 16 & 76.2 \\
\hline & & Diffuse & 5 & 23.8 \\
\hline \multirow{3}{*}{ Diseased } & 41 & Negative & 7 & 17.1 \\
\hline & & Focal & 22 & 53.7 \\
\hline & & Diffuse & 12 & 29.3 \\
\hline \multicolumn{5}{|c|}{ PR intensity } \\
\hline \multirow{3}{*}{ Healthy } & 21 & Weak & 6 & 28.6 \\
\hline & & Moderate & 7 & 33.3 \\
\hline & & Strong & 8 & 38.1 \\
\hline \multirow{4}{*}{ Diseased } & 41 & Negative & 7 & 17.1 \\
\hline & & Weak & 15 & 36.6 \\
\hline & & Moderate & 5 & 12.2 \\
\hline & & Strong & 14 & 34.1 \\
\hline \multicolumn{5}{|c|}{ ER and PR percentage (combined) } \\
\hline \multirow{3}{*}{ Healthy } & 21 & ER focal + PR focal & 5 & 23.8 \\
\hline & & ER diffuse + PR diffuse & 4 & 19.0 \\
\hline & & Mix Pattern & 12 & 57.1 \\
\hline \multirow{3}{*}{ Diseased } & 41 & ER focal + PR focal & 5 & 12.2 \\
\hline & & ER diffuse $+P R$ diffuse & 12 & 29.3 \\
\hline & & Mix Pattern & 24 & 58.5 \\
\hline \multicolumn{5}{|c|}{ ER and PR intensity (combined) } \\
\hline \multirow{2}{*}{ Healthy } & 21 & ER strong + PR strong & 8 & 38.1 \\
\hline & & Mix pattern & 13 & 61.9 \\
\hline \multirow{3}{*}{ Diseased } & 41 & ER moderate + PR moderate & 2 & 4.9 \\
\hline & & ER strong + PR strong & 12 & 29.3 \\
\hline & & Mix pattern & 27 & 65.9 \\
\hline & & & Con & inued.. \\
\hline
\end{tabular}




\begin{tabular}{|c|c|c|c|c|c|c|}
\hline \multicolumn{7}{|c|}{ Differences between groups } \\
\hline Category & Group & $\mathbf{N}$ & $\chi^{2}$ value & p-value & OR & $95 \% \mathrm{Cl}$ \\
\hline \multicolumn{7}{|c|}{ Disease distribution according to various categories } \\
\hline \multirow[t]{2}{*}{ Gender } & Male & 40 & \multirow[t]{2}{*}{0.66} & \multirow[t]{2}{*}{0.42} & \multirow[t]{2}{*}{1.60} & \multirow{2}{*}{$0.51-4.98$} \\
\hline & Female & 22 & & & & \\
\hline \multirow[t]{2}{*}{ Side } & Right & 31 & \multirow[t]{2}{*}{0.65} & \multirow{2}{*}{0.42} & \multirow[t]{2}{*}{0.65} & \multirow{2}{*}{$0.22-1.87$} \\
\hline & Left & 31 & & & & \\
\hline \multirow[t]{2}{*}{ ER \% } & Focal & 13 & \multirow[t]{2}{*}{1.11} & \multirow{2}{*}{0.29} & \multirow[t]{2}{*}{1.94} & \multirow{2}{*}{$0.56-6.77$} \\
\hline & Diffuse & 49 & & & & \\
\hline \multirow[t]{2}{*}{ ER intensity } & Moderate & 14 & \multirow[t]{2}{*}{1.25} & \multirow{2}{*}{$0.35 *$} & \multirow[t]{2}{*}{0.45} & \multirow{2}{*}{$0.11-1.85$} \\
\hline & Strong & 48 & & & & \\
\hline \multirow[t]{3}{*}{ PR \% } & Negative & 7 & \multirow{3}{*}{4.89} & & - & \\
\hline & Focal & 38 & & $0.10 *$ & & - \\
\hline & Diffuse & 17 & & & & \\
\hline PR intensity & Negative & 7 & & & - & \\
\hline & Weak & 21 & 7.12 & & & \\
\hline & Moderate & 12 & & $0.07 *$ & & - \\
\hline & Strong & 22 & & & & \\
\hline$E R+P R \%$ & ER focal + PR focal & 10 & 73 & & - & \\
\hline & Mix pattern & 36 & 1.13 & $0.42 *$ & & - \\
\hline & ER diffuse + PR diffuse & 16 & & & & \\
\hline ER+PR intensity & ER moderate + PR moderate & 2 & & & - & \\
\hline & ER strong + PR strong & 20 & 1.39 & $0.62 *$ & & - \\
\hline & Mix pattern & 40 & & & & \\
\hline Gender distributi & rding to various categories & & & & & \\
\hline Diagnosis & Healthy & 21 & 0.66 & 0.42 & 1.60 & $051-498$ \\
\hline & Diseased & 41 & & & & $0.51-4.98$ \\
\hline Side & Right & 31 & 0.28 & 0.60 & 0.75 & \\
\hline & Left & 31 & & & & $0.27-2.14$ \\
\hline ER \% & Focal & 13 & 1.11 & $0.35^{*}$ & 2.11 & \\
\hline & Diffuse & 49 & & & & $0.51-8.6 /$ \\
\hline ER intensity & Moderate & 14 & 1.56 & $0.34 *$ & 2.40 & \\
\hline & Strong & 48 & & & & $0.59-9.16$ \\
\hline PR \% & Negative & 7 & 312 & $023 *$ & - & \\
\hline & Focal & 38 & 3.12 & 0.25 & & - \\
\hline & Diffuse & 17 & & & & \\
\hline PR intensity & Negative & 7 & & & - & \\
\hline & Weak & 21 & 5.46 & $0.17 *$ & & \\
\hline & Moderate & 12 & & & & - \\
\hline & Strong & 22 & & & & \\
\hline$E R+P R \%$ & ER focal + PR focal & 10 & 259 & $032 *$ & - & \\
\hline & Mix pattern & 36 & 2.59 & $0.32^{*}$ & & - \\
\hline & ER diffuse + PR diffuse & 16 & & & & \\
\hline $\mathrm{ER}+\mathrm{PR}$ intensity & ER moderate + PR moderate & 2 & 5.54 & $0.07 *$ & - & - \\
\hline
\end{tabular}

Among the diseased, focal ER positivity was seen in seven (17.1\%) and diffuse ER positivity was seen in 34 cases (82.9\%). Eleven $(26.8 \%)$ showed moderate ER intensity and 30 cases $(73.2 \%)$ showed strong intensity. Focal PR positivity was observed in $22(53.7 \%)$ and diffuse positivity was seen in 12 cases $(29.3 \%)$, while seven $(17.1 \%)$ were negative. Fifteen $(36.6 \%)$ showed weak PR intensity, five (12.2\%) showed moderate intensity and $14(34.1 \%)$ showed strong intensity, while seven cases (17.1\%) were negative. Most showed presence of diffuse ER and focal PR, and strong intensity. A consider- able proportion (41.9\%) showed presence of ER and PR in either focal or diffuse pattern, correlating with each other.

Among healthy specimens, focal ER positivity was seen in six (28.6\%) and diffuse ER positivity was seen in 15 (71.4\%). Three (14.3\%) showed moderate ER intensity and 18 (85.7\%) showed strong intensity. Focal PR positivity was seen in $16(76.2 \%)$ and diffuse PR positivity was seen in five specimens $(23.8 \%)$. Six $(28.6 \%)$ showed weak, seven $(33.3 \%)$ showed moderate and eight (38.1\%) showed strong PR intensity. 
Table II: Correlations between factors. The correlation coefficients (Spearman's rho) are given.

\begin{tabular}{|c|c|c|c|c|c|c|c|c|c|}
\hline & Diagnosis & Gender & Side & ER \% & $\begin{array}{c}\text { ER } \\
\text { Intensity }\end{array}$ & PR \% & $\begin{array}{c}\text { PR } \\
\text { Intensity }\end{array}$ & $\begin{array}{l}\text { ER and PR \% } \\
\text { (Combined) }\end{array}$ & $\begin{array}{c}\text { ER and PR Intensity } \\
\text { (Combined) }\end{array}$ \\
\hline Diagnosis & 1 & 0.10 & -0.10 & 0.13 & -0.14 & -0.07 & -0.20 & 0.16 & 0.02 \\
\hline Gender & & 1 & -0.07 & 0.13 & 0.16 & 0.20 & 0.25 & 0.20 & -0.20 \\
\hline Side (kidney) & & & 1 & 0.12 & 0.08 & -0.05 & 0.02 & 0.05 & -0.07 \\
\hline ER \% & & & & 1 & $0.48 * *$ & 0.21 & 0.16 & $0.67 * *$ & -0.03 \\
\hline ER intensity & & & & & 1 & 0.19 & $0.33^{* *}$ & 0.25 & -0.19 \\
\hline PR \% & & & & & & 1 & $0.75^{* *}$ & $0.69 * *$ & $-0.53^{* *}$ \\
\hline PR intensity & & & & & & & 1 & $0.47 * *$ & $-0.78^{* *}$ \\
\hline ER/PR \% (combined) & & & & & & & & 1 & $-0.36 * *$ \\
\hline $\begin{array}{l}\text { ER and PR intensity } \\
\text { (combined) }\end{array}$ & & & & & & & & & 1 \\
\hline
\end{tabular}
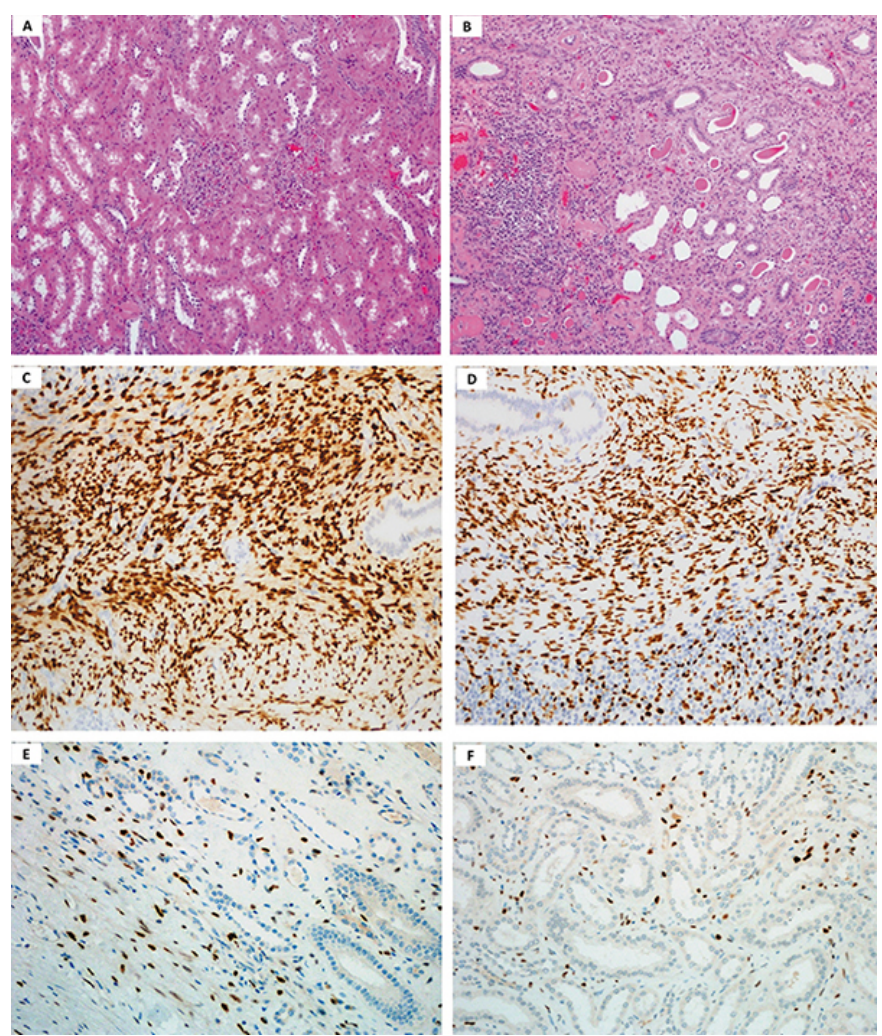

Figure 1: Histological and immunohistochemical characteristics of renal samples. (A) Low power magnification image showing healthy kidney parenchyma. (B) Low power magnification image of kidney parenchyma chronic pyelonephritis with numerous chronic inflammatory cells mostly lymphocytes in the stroma. (H\&E x 400). (C) Low power magnification image showing ER positive immunohistochemical staining in the pyelonephritis kidney stroma. (D) Low power magnification image showing $P R$ positive immunohistochemical staining in pyelonephritis kidney stroma. (x10). (E) Low power magnification image showing ER positive immunohistochemical staining in the healthy kidney stroma. (F) Low power magnification image showing PR positive immunohistochemical staining in the healthy kidney stroma $(x 10)$.

Figure 1 shows H\&E stained renal biopsies in healthy (Panel-A) and chronic pyelonephritis (Panel-B). Healthy renal specimens showed typical normal kidney parenchyma; whereas, the chronic pyelonephritis specimens showed chronic inflammatory cell infiltrate, degenerative tubules with thyroidization and fibrosis. The stromal cells were also identified having spindle shaped nuclei and indistinct cytoplasm near the pelvic area. Figure- 1 also shows stromal ER and PR staining (IHC). Panel C and D showed ER and PR in chronic pyelonephritis, respectively. The stromal cells are seen with typical oval to elongated nuclei. Panels $E$ and $F$ showed ER and PR in healthy. A higher ER and PR presence is identified in chronic pyelonephritis.

Chi-square test and odds ratio values to analyse the difference of expression and intensity of $E R$ and $P R$ between groups are given in Table I. As shown, the difference in ER and PR expression and intensity did not reach statistical significance between healthy and diseased kidneys.

Correlations (Spearman's rho) between expression and intensity of ER and PR is given in Table II. There was a significant positive correlation between ER expression and intensity, PR expression and intensity, as well as combined ER and PR expression.

\section{DISCUSSION}

This study showed that stromal ER was positive in all specimens; whereas, PR was positive in majority. Despite a trend of intense IHC staining and thus higher expression of ER and $\mathrm{PR}$ in pyelonephritis as compared to healthy specimen, no difference reached statistical significance.

The steroid hormones are known to regulate gene expression and may contribute to increased cellular proliferation. An example is hormone-dependent cancers in gonadal tissue ${ }^{4}$ as well as non-gonadal tissues. ${ }^{5,6,10,14}$ As mentioned above, a link between chronic inflammation and carcinogenesis has been reported, ${ }^{2}$ hence elevated C-reactive protein (CRP) levels have also found associated with an increased cancer risk. Various pathways link chronic inflammation, DNA damage repair, mutagenesis and cancer. ${ }^{15}$ Chronic inflammation leads to generation of reactive oxygen and nitrogen species (RONs) leading to accumulated DNA mutations ${ }^{16}$ and cancer. ${ }^{17}$ Recent evidence also suggests that chronic inflammation may change the expression of estrogen receptors $;^{18}$ which in turn, potentially leads to aberrant cellular growth signal. ${ }^{14}$ Thus, we may hypothesize that chronic pyelonephritis may predispose to renal cancer, at 
least in part by modulating gonadal hormone receptors among other factors, such as NFKB. ${ }^{8}$ Further research is needed in this regard.

An advantage of this study is its comparative design that is considered relevant and appropriate especially where sample size is limited, like in this study. The subject has been studied in relationship to renal neoplasia, but not chronic pyelonephritis, thus hinting towards an important missing link. To the best of authors' knowledge, this is the first study of its kind where chronic pyelonephritis as well as healthy renal tissues were compared. There are some limitations, too. This study employed convenience sampling in a single centre and needs validation for generalisation. There was a visible difference on IHC between diseased and healthy renal tissues in terms of ER/ PR positivity, where ER and PR expression appeared stronger and diffuse in chronic pyelonephritis. However, the results fell short of statistical significance. This could have been due to our limited sample size compounded by statistical modelling.

As evident from these results, a more conservative statistical approach was applied due to limited sample size, thus making statistical significance difficult to achieve. Further, the healthy tissues were obtained from kidneys nephrectomised for renal neoplasia. This raises the possibility of an aberrant expression of baseline ER and PR which might have further compromised the chances of getting a statistical significance. Usually, healthy renal specimens are obtained through autopsies, which was unlikely in this study setting, because autopsies are done in suspected homicides which is not a common occurrence.

The authors recommend that the study should be validated in a setting where completely normal renal tissues could be obtained, such as from cadavers, for comparison, of course with a sample size as feasibly larger as possible.

\section{CONCLUSION}

There was a trend of increased diffuse renal stromal expression of ER and PR in chronic pyelonephritis as compared to healthy specimens. Although visually distinct, the renal stromal ER/PR expression in chronic pyelonephritis did not differ significantly from healthy one.

FUNDING: This study was supported by a grant from Alfaisal University, Riyadh, Saudi Arabia (IRG No.313020109151).

\section{ETHICAL APPROVAL:}

The study was conducted after approval from Research Ethics Committee, King Faisal Specialist Hospital and Research Centre, Riyadh, Saudi Arabia (Ref: ORA/0414/37).

\section{CONFLICT OF INTEREST:}

The authors declared no conflict of interest.

\section{AUTHORS' CONTRIBUTIONS:}

MAB: Planned and conducted the study, obtained the research grant, wrote the manuscript and managed the project at the participating institution.

MA: Planned and conducted the study.

NAA: Analysed the data and wrote the manuscript.

AAMA: Planned and conducted the study and inducted patients for the study.

JK: Wrote the manuscript.

TOAH: Planned and conducted the study, wrote the manuscript and supervised the project at the participating institution.

\section{REFERENCES}

1. Tickoo SK, Gopalan A, Tu JJ, Harik LR, Ahmadie AA, Fine SW, et al. Estrogen and progesterone-receptor positive stroma as a non-tumorous proliferation in kidneys: A possible metaplastic response to obstruction. Modern Pathology 2008; 21(1):60-5. doi: 10.1038/modpathol.3800958.

2. Guo YZ, Pan L, Du CJ, Ren DQ, Xie XM. Association between C-reactive protein and risk of cancer: A meta-analysis of prospective cohort studies. Asian Pac J Cancer Prev 2013; 14(1):243-8. doi: 10.7314/apjcp.2013.14.1.243.

3. Xue XT, Zhang T, Cui SJ, He DQ, Wang XD, Yang RL, et al. Sexual dimorphism of estrogen-sensitized synoviocytes contributes to gender difference in temporomandibular joint osteoarthritis. Oral Dis 2018; 24(8):1503-13. doi: 10.1111/odi.12905.

4. Butt AJ, Sergio CM, Inman CK, Anderson LR, McNeil CM, Russell AJ, et al. The estrogen and c-Myc target gene HSPC111 is over-expressed in breast cancer and associated with poor patient outcome. Breast Cancer Res 2008; 10(2):R28. doi: 10.1186/bcr1985.

5. Rennoll S, Yochum G. Regulation of MYC gene expression by aberrant Wnt/B-catenin signaling in colorectal cancer. World J Biol Chem 2015; 6(4):290-300. doi: 10.4331/ wjbc.v6.i4.290.

6. Shroff EH, Eberlin LS, Dang VM, Gouw AM, Gabay M, Adam $\mathrm{SJ}$, et al. MYC oncogene overexpression drives renal cell carcinoma in a mouse model through glutamine metabolism. Proc Natl Acad Sci USA 2015; 112(21): 6539-44. doi: 10.1073/pnas.1507228112.

7. Zhang L, Zhu Y, Cheng H, Zhang J, Zhu Y, Chen $\mathrm{H}$, et al. The increased expression of estrogen related receptor $\alpha$ correlates with wnt $5 \mathrm{a}$ and poor prognosis in patients with glioma. Mol Cancer Ther 2019; 18(1):173-84. doi: 10.1158/1535-7163.MCT-17-0782.

8. Wood CE, Branstetter D, Jacob AP, Cline JM, Register TC, Rohrbach K, et al. Progestin effects on cell proliferation pathways in the postmenopausal mammary gland. Breast Cancer Res 2013; 15(4):R62. doi: 10.1186/bcr3456.

9. Beuselinck B, Jean-Baptiste J, Couchy G, Job S, De Reynies $A$, Wolter $\mathrm{P}$, et al. RANK/OPG ratio of expression in primary clear-cell renal cell carcinoma is associated with bone metastasis and prognosis in patients treated with anti-VEGFR-TKIs. Br J Cancer 2015; 113(9):1313-22. doi: 10.1038/bjc.2015.352.

10. Zou L, Zhang X, Xiang H. Malignant mixed epithelial and stromal tumor of the kidney: The second male case and review of literature. Int J Clin Exp Pathol 2014; 7(5): 2658-63. 
11. LeRoy MA, Rao P. Angiomyolipoma with Epithelial Cysts. Arch Pathol Lab Med 2016; 140(6):588-93. doi: 10.5858/arpa.2015-0170-RS.

12. Sun L, Gao Z, Luo L, Tan H, Zhang G. Estrogen affects cell growth and IGF-1 receptor expression in renal cell carcinoma. Onco Targets Ther 2018; 11:5873-8. doi: 10.2147/OTT.S172149.

13. Yu CP, Ho JY, Huang YT, Cha TL, Sun GH, Yu DS, et al. Estrogen inhibits renal cell carcinoma cell progression through estrogen receptor- $\beta$ activation. PLoS One 2013; 8(2):e56667. doi:10.1371/journal.pone.0056667.

14. Meyer zu Schwabedissen HE, Tirona RG, Yip CS, Ho RH, Kim RB. Interplay between the nuclear receptor pregnane $X$ receptor and the uptake transporter organic anion transporter polypeptide 1A2 selectively enhances estrogen effects in breast cancer. Cancer Res 2008; 68(22):
9338-47. doi: 10.1158/0008-5472.CAN-08-0265.

15. Kidane D, Chae WJ, Czochor J, Eckert KA, Glazer PM, Bothwell $A L$, et al. Interplay between DNA repair and inflammation, and the link to cancer. Crit Rev Biochem Mol Biol 2014; 49(2):116-39. doi: 10.3109/10409238.2013. 875514.

16. Nathan C, Cunningham-Bussel A. Beyond oxidative stress: An immunologist's guide to reactive oxygen species. Nat Rev Immunol 2013; 13(5):349-61. doi:10.1038/nri3423.

17. Kiraly O, Gong G, Olipitz W, Muthupalani S, Engelward BP. Inflammation-induced cell proliferation potentiates DNA damage-induced mutations in vivo. PLoS Genet 2015; 11(2):e1004901. doi: 10.1371/journal.pgen.1004901.

18. Aravamudan B, Goorhouse KJ, Unnikrishnan G, Thompson MA, Pabelick CM, Hawse JR, et al. Differential Expression of Estrogen Receptor Variants in Response to Inflammation Signals in Human Airway Smooth Muscle. J Cell Physiol 2017; 232(7):1754-60. doi: 10.1002/jcp.25674. 